\title{
M-learning Mode in Foreign Language Teaching and Learning Fu Bo ${ }^{1, a}$, Song Yinqiu ${ }^{1, b}$, Zhang Jingwei ${ }^{1, c}$ \\ ${ }^{1}$ Jilin Agricultural University, College of Foreign Languages, Changchun,130118,China \\ aivy510@126.com, byqsong1967@yahoo.com, c422820075@qq.com
}

Keywords: M-learning;mobile technology; language teaching and learning; learners

\begin{abstract}
M-learning, short for mobile learning, is a brand new form of learning, which means to gain learning information and education resources as well as education service with the aid of wireless mobile communication technology and equipment. M-learning is the binding product of education and modern information technology, and considered as a new variant of distance education. This learning mode must be closely related with foreign language learning, since language teaching and learning always combines with modern information technology simultaneously. This article explains the basic concepts of M-learning, and the theoretical basis and significance of M-learning application into foreign language learning. Strategies available in different stages for M-learning are also presented. With the basis of a lot of study in foreign countries, this article also points out it needs foreign language educators' active and effective participation in terms of research and discussion of M-learning in foreign language teaching and learning.English teachers play an important role in inspiring learners' enthusiasm in the process of M-learning. English learners' persistence in M-learning is also crucial. Developing the habit of learning with mobile tools will bring a lot of benefit for one's lifelong learning.
\end{abstract}

\section{Introduction}

Portable wireless communication devices, a rich mixture of network resources and constant outpouring socialized software have definitely become an indispensable part in modern life, especially for young college students. In the field of education, the application of the wireless mobile technology contributes greatly to a new learning mode, namely mobile learning. Mobile learning (M-learning) refers to kind of distance learning with modern communication terminals, such as smart phones or PDA anytime and anywhere under the guidance of the idea of lifelong learning. M-learning is widely used due to the development of wireless communication technology and widespread application. Its popularization and development will inevitably cause the great changes in education technology and means and it will become an indispensable part of learning form in the near future and have a nice prospect. To make mobile technology serve modern education has become a hot research item among educators, which means great value in education application. What educators are concerned is that the way to make the mobile technology play as many advantages as possible when do their teaching. To master the theoretical basis and the implementation method of M-learning ought to benefit the mobile learners, and some strategies for the design of mobile learning would help the progress of relevant researches in this field.

\section{Theoretical basis for M-learning}

M-learning is closely related with some learning theories such as informal learning, constructive learning, situated learning, action learning and experiential learning. On the one hand, these new learning theories lay a solid foundation for M-learning. On the other hand, M-learning supplies these learning theories in application new technical means and methods.

1) Informal learning. What informal learning emphasizes is context sensibility and takes learning as the essence of human's communication exchange. Leaning is characterized by both individuality (thinking, reading etc.) and sociability(lecture, discussion etc.). Learning can be done at any time, but it is influenced by either environment or concrete situation. Informal learning is 
intentional or optional, so the learner can get new information by taking conversation, watching TV, scanning newspapers or even experiencing an events. Learning in such generalized sense is done outside the classroom or in one's daily life. M-learning is of vital significance in sustaining informal learning and lifelong learning.

2) Constructive learning. Constructive learning is an active learning process for learners, who construct new knowledge on the basis of available knowledge in existence. Mobile technology places learners in real situation and offers them passageway to get help whenever and wherever possible.

3) Situated learning. Situated learning theory regards learning is kind of activity of self-construction significance and identity based on social cultural situation or interaction. It puts stress on the effect of the exterior learning environment for learning. What it advocates is field study in the natural environment and social investigation or interview in the community. Mobile communication technology makes it possible to gain knowledge in various fields at any time and any place. Therefore, M-learning supplies situated learning theory with technical assistance, while situated learning theory offers theoretical foundation for M-learning.

4) Action learning. Action learning refers to learning in practical activity, that is, the problem-centered learning team solves the problem under the guide of external specialists and team members by active learning, constant questioning and sharing experiences. In learning activities, one important factor to prove that learning is successful or unsuccessful is whether learners can get useful knowledge needed conveniently or not. The learning activity supported by mobile learning technology tends to exert the advantage of the action learning and optimizes the learning effect.

5) Experiential learning. Experiential learning theory emphasizes the importance of abstract thinking, practical activity, experience development and reflective observation. It also points out the main feature of effective learning is the interactive and spiral escalation of these four aspects mentioned above. Abstract thinking and practical activity need abundant knowledge and information as bases. To gain knowledge and information learners need timely and conveniently during the process of abstract thinking and practical activity with the aid of mobile learning technology will improve the learners' motivation greatly and better learning effect.

The above five standards of classification can be found in most foreign languages teaching theories, to be specific, situated learning in situated teaching method, constructive learning and action learning in social and cultural perspective for foreign language teaching, informal learning in second language acquisition. As a consequence, theoretically, it is feasible and practical to apply the mobile technology in English language teaching and learning.

\section{Significance of M-learning for English teaching and learning}

M-learning means learners can learn what he/she wants to learn whenever and wherever, and the learning time and learning place are rather flexible. It inherits five key factors of distance learning: the flexibility of teaching time and space; initiative of choosing learning contents; plasticity of learning process; plurality of teaching resources and diversity of teaching modes. Unique and efficient teaching mode can be formed by the application of M-learning in English language teaching and learning.

Traditional language teaching means the language teacher imparts knowledge in classroom and the learner' language level is restrained by the teacher's teaching method, teaching level and teaching materials. Language learners can not contact with authentic and fashionable English language, meanwhile, the online resources are wasted for nothing. Language is a tool for communication and English is no exception. Learners can have more vivid learning experience with the assistance of the learning materials, video and audio online than the regular class lecture.

Learners usually have different language learning needs in different times, however, the textbooks remain the same for several years due to various reasons. Under such circumstance, teachers should turn to internet and take advantage of teaching resources online. The learners' expectations for learning English are different due to different majors. Some learners want to make good use of English in jobs after graduation; some learners choose to go aboard for further study; 
some learners just hope to pass CET-4 and postgraduate entrance exam. So in terms of learning materials, teachers should help them choose major-related and practical articles. The topics that are wildly discussed by English speakers are suitable for learners' oral English practice such as sports which become commonly used in social communication. And these teaching and learning resources are available to all M-learners via Internet.

\section{Integration of M-learning and college teaching and learning}

Nowadays, nearly all college students have mobile phone, and computers available in library or in dormitory. Most students have MP3 or MP3 function in mobile phones and many universities and college are installed with WiFi network and related equipment. So learners are provided with conditions for M-learning.

English teachers should make a concrete M-learning plan at beginning of every semester. The teaching contents can be set with the following standards: 1.The relatively inapplicable materials can be replaced by interesting articles online with contemporary character. 2.Different majors should have different or major-related learning contents, such as professional vocabulary and professional reading. 3. Short and excellent essays with enlightening significance should be collected and sorted for the youngsters. English teachers can recommend learners some websites with different styles to meet different learning purposes in or out of English class. If learners need to have listening practice, they can enter such websites as www.putclub.com or www.hjenglish.com. In order to drill reading skill learners can log on www.economist.com or www.nytimes.com. For speaking practice, learners can download the content of the new concept English. These websites are popularized in college English teaching in China, and help countless English learners succeed in learning the language. English teachers should recommend correspondent websites to help learners solve their problems they meet in learning.

In the course of teaching, teachers can upload learning materials onto the group share area and learners can download useful information to study. Teachers also can share some new English words, short essays or English songs in Blog for learners to help them learn English anywhere and anyplace. In order to practice writing skill, learners can e-mail their writing to teachers or shared in group to have peer revision in ESL writing lecture. Learners can study by means of various network tools randomly and without any pressure. English learner also share their opinions of learning experience or learning resources through all kinds of tools, which is sometimes complementary to teachers' materials and can have the effect of interaction at any time.

English teachers play a role of guider, organizer and supervisor during the M-learning and teachers must make sure that the language online is healthy and focus on the feedback from learners towards the learning materials. M-learning mode is flexible as far as time and place are concerned. There are lot of other lure in the virtual world and some learners cannot resist it. Sometimes the learning effect is not satisfactory due to laziness or poor self-control ability. Therefore, English teachers must have test for learner's M-learning effect for 10 minutes in each period by asking learners questions individually or group unit. Different questions should be designed for different learning content. For example, learner can be asked to recite an English proverb or guess the meaning of words released by the teacher. Or learner's writing can be presented to all others and teacher's suggestion will be made explicit to all, so learners can compare others' with their own to find the strength and weakness. English teachers can also ask learners to sing an English song or summarize the theme of an English movie or restate excellent dialogue in the movie and so on. Questions can be in totally different forms but what is most important is to do it persistently.

\section{Strategies for each stage in M-learning}

At the initial stage of M-learning, teachers can give learners guidance about the usage of network tools to make it sure that every learner can use it skillfully. Teachers can turn to network technological professionals or students who are better at handling network operation. Or learners can be divided into several groups, and there is a learner who has good network skill or good 
English proficiency, thus, it can take full advantage of each member in the group to have much better learning effect.

During the process of M-learning, English teachers should give learners ambiguous learning task each time. Currently, there are CD in most textbooks and CD contents are mainly carried in the form of MP3, so teachers can arrange learner to learn the textbook content by the way of M-learning out of class. Learner can search for some background knowledge around a certain topic, read related document, make an investigation or write a report. After sufficient preparation outside class, English learners state or discuss certain problems in class under the guidance of English teachers. By M-learning, English learners can take advantage of extracurricular time fully and dynamically integrate the learners' English competence of listening, speaking, reading, writing and translating.

As to make the best of extracurricular time, especially compared with traditional second class to learn such as English corner, M-learning can benefit learners much more with abundant learning resources online. English teachers have the responsibility to make learners realize the importance of autonomous learning and cooperative learning. Learners are encouraged to learn outside class with online resources and mobile tools. Developing the habit of learning with mobile tools will bring a lot of benefit for one's lifelong learning. English teachers play an important role in inspiring learners' enthusiasm in the process of M-learning. All in all, M-learning is kind of learning accumulated through long time, and only persistence can gain better effect.

\section{Summary}

With the development of communication technology, the advancement of digitization process, the popularization of modern technological education, large area coverage of wireless network and the subjective and objective needs of college English teaching reform, M-learning and college English teaching and learning should be integrated inevitably and necessarily. M-learning mode will exert an far-reaching influence on the effect of college English teaching and learning. Undoubtedly, quite different from traditional teaching methods, M-learning requires English teachers to make great efforts in changing teaching mode, teaching resources, teachers' roles and evaluation mechanism. M-learning mode in college English teaching and learning will offer better service for teachers' teaching quality and learners' language learning effect.

\section{References}

[1] Babak Ghasemi, Masoud Hashemi. ICT: Newwave in English language learning/ teaching J. Procedia Social and Behavioral Sciences (2011)

[2] McDevitt Barb. Learner autonomy and the need for learner training J. Language Learning Journal, (1997)

[3] Smordal O, Gregory J, Langseth K J. PDAs in medical education and Practice C. Milrad M. Proceedings of IEEE International Workshop on Wireless and Mobile Technologies in Education, Los Alamitos: IEEE Computer Society, (2002)

[4] Alesksander Dye et al. Mobile education- a glance at the future [EB/OL], http://www. nettskolen.com/

[5] Ken Beaty. Teaching and Researching Computer-assisted Language Learning M. Foreign Language Teaching and Research Press. (2007)

[6]Paul Harris. Go in Mobile [EB/OL], http://www.learningcircuits.org/2001/jul2001/harris.html.

[7] Kong K. A comparison of the linguistic and interactive features of language learning websites and textbooks J. Computer Assisted Language Learning(2009) 